\title{
Feasibility of Activating Electronic Health Care System in Ibn Rushed Hospital
}

\author{
Hassan Naeem Kareem ${ }^{1}$, Lujain Anwer Abood ${ }^{2}$ \\ ${ }^{1}$ PhD Student/Community Health Nursing Department/College of Nursing-University of Baghdad/Iraq, ${ }^{2}$ Assistant \\ Professor/Community Medicine Department/College of Al-kindy Medicin-University of Baghdad/Iraq
}

\begin{abstract}
A descriptive study was conducted on health care providers them use electronic health care system and patients or clients in Ibn Rushed Teaching Hospital in Baghdad-Iraq. To evaluate the feasibility of activating electronic health care system, Data was collected using a developed self-administrated questionnaire; data was collected from March $20^{\text {th }}, 2019$ to May $6^{\text {th }} 2019$.

A purposive sample (non-probability sample) were selected $(\mathrm{N}=115)$ the study sample was divided into two parts, the first part is healthcare providers and their number (65), the number of physicians is (32) and the number of nurses is (33). The second part of the sample is patients or clients and their number (50).

Data were analyzed through the application of descriptive and inferential statistical approaches by using Statistical Package for Social Science (SPSS) version 19.

For health care providers, the findings for revealed that most of the respondents were males with age's range from (31 to 39) years old, most of the respondents were physicians with (8 to 17) years' experience. Most of the responses regarding of feasibility of activating electronic health care system, there are feasibility from activating electronic health care system (83\%).

As for results patients and clients Most of the respondents were males with age's range from (35 to 55) years old, level education for respondents were Primary and Preparatory education. Most of the responses regarding of feasibility of activating electronic health care system, there are feasibility from activating electronic health care system $(90 \%)$.

The study recommended the government should be well informed about the benefits and latest innovation in e-Health so as to encourage appropriate allocation of budget, so that e-Health policy implementation can be taken more seriously. Highly recommendation the Ministry of Health to impose and generalize the experience of the electronic health care system in all hospitals in the country. Highly recommended that the educational sector inculcate e-Health into the curriculum for the integration of IT solutions into healthcare to flow successfully, this will provide health care givers graduating from learning institutions systemic training and education on the use of the e-Health. Recommended for further studies to adopt both quantitative and qualitative research approaches in similar studies to generate more responses from participants. This would help reveal whether or not the intended benefits of the implemented E-Health to patients are actually realized.
\end{abstract}

Keywords: Feasibility, electronic health care system.

\section{Introduction}

Electronic health (E-Health) is one of the 21st century innovations in healthcare. It is an umbrella term, which portrays the joined utilization of electronic correspondence and data innovation in the health/ wellbeing division as well as the use of digital data transmitted, stored and recovered electronically for clinical, educational and administrative purposes, both at the local site and at distance ${ }^{(1)}$. Since the inauguration of e-health, it has transformed the healthcare sector 
and embraced it's description by Intel as a concerted effort undertaken by leaders in health care and hi-tech industries to fully harness the benefits available through convergence of the Internet and health care ${ }^{(2)}$. E-Health or health information technology (IT) as the case may be has the potential to improve the health of individuals and the performance of providers, yielding improved quality, cost savings and greater engagement by patients in their own health care ${ }^{(3)}$.

E-Health is the use of information and communication technologies (ICT) for health as defined by the World Health Organization (WHO). E-Health has been a priority for the World Health Organization (WHO) since 2005, when the World Health Assembly resolution WHA58.28 was adopted: "e-Health is the cost-effective and secure use of information communication technologies (ICT) in support of health and health related fields, including health-care services, health surveillance, health literature and health education, knowledge and research" (4).

\section{Methodology}

A descriptive study was conducted on health care providers them use electronic health care system and patients or clients in Ibn Rushed Teaching Hospital in Baghdad-Iraq. To evaluate the feasibility of activating electronic health care system, Data was collected using a developed self-administrated questionnaire; data was collected from March 20th, 2019 to May 6th 2019.

The tool of the study is the questionnaire, which has been constructed and design for the purpose of the study after extensive reviews of available literature and related studies. The study instrument consists of two parts. The first part includes health care providers questionnaire, the second part includes patients or clients questionnaire,

A purposive sample (non-probability sample) were selected $(\mathrm{N}=115)$ the study sample was divided into two parts, the first part is healthcare providers and their number (65), the number of physicians is (32) and the number of nurses is (33). The second part of the sample is patients or clients and their number (50).

Data were analyzed through the application of descriptive and inferential statistical approaches by using Statistical Package for Social Science (SPSS) version 19.

\section{Result of the Study}

Table (1) distribution of the client or patient by their demographic data

\begin{tabular}{|l|l|c|c|c|}
\hline Demographic data & Rating and scoring & Frequency & Percent & Cumulative Percent \\
\hline \multirow{5}{*}{ Gender } & Male & 31 & 62 & 62 \\
\cline { 2 - 5 } & Female & 19 & 38 & 100 \\
\hline \multirow{5}{*}{ Age/years } & $<=25$ & 5 & 10 & 10 \\
\cline { 2 - 5 } & $26-35$ & 8 & 16 & 26 \\
\cline { 2 - 5 } & $36-45$ & 17 & 34 & 60 \\
\cline { 2 - 5 } & $46-55$ & 16 & 32 & 92 \\
\cline { 2 - 5 } & 56 and more than & 4 & 8 & 100 \\
\hline \multirow{5}{*}{ Level of education } & Uneducated & 8 & 16 & 16 \\
\cline { 2 - 5 } & Read and write & 6 & 12 & 28 \\
\cline { 2 - 5 } & Primary school & 15 & 30 & 58 \\
\cline { 2 - 5 } & Intermediate school & 2 & 2 & 90 \\
\cline { 2 - 5 } & Preparatory school & 50 & 10 & 100 \\
\cline { 2 - 5 } & Bachelor's Degree & 18 & \\
\cline { 2 - 5 } & Total & & 100 & \\
\hline
\end{tabular}

This table show that the study results for study sample by their demographic data that indicate the majority of the study samples are male $(62 \%)$ and age is (36-45) years old within age groups (34\%). Regarding level of education is preparatory school the majority of the study sample (36\%). 
Table (2) Distribution of the Study sample (patients and clients) by their responses to the feasibility of activating electronic health care system

\begin{tabular}{|l|l|c|c|c|}
\hline Overall Domains & Rating and Scoring & Frequency & Percent & Cumulative Percent \\
\hline \multirow{4}{*}{ Feasibility Domain } & Feasibility & 45 & 90 & 90 \\
\cline { 2 - 5 } & Some Extent Feasibility & 5 & 10 & 100 \\
\cline { 2 - 5 } & Not Feasibility & 0 & 0 & \\
\hline
\end{tabular}

This table show that the study results that indicate overall assessment for the responses of study samples are most of their responses about feasibility domain is feasibility (90\%) for client or patient about application of electronic health system.

Table (3) Distribution of the health care providers by their demographic data

\begin{tabular}{|l|l|c|c|c|}
\hline Demographic data & Rating and scoring & Frequency & Percent & Cumulative Percent \\
\hline \multirow{5}{*}{ Gender } & Male & 41 & 63.1 & 63.1 \\
\cline { 2 - 5 } & Gender & 24 & 36.9 & 100 \\
\hline \multirow{5}{*}{ Age/years } & $<=30$ & 9 & 13.8 & 13.8 \\
\cline { 2 - 5 } & $31-39$ & 32 & 49.2 & 63.1 \\
\cline { 2 - 5 } & $40-48$ & 11 & 17 & 80 \\
\cline { 2 - 5 } & $49+$ & 13 & 20 & 100 \\
\hline \multirow{5}{*}{ Occupation } & Physician & 32 & 49.2 & 49.2 \\
\cline { 2 - 5 } & College nurse & 7 & 21.5 & 60 \\
\cline { 2 - 5 } & Medical assistance & 14 & 18.5 & 81.5 \\
\cline { 2 - 5 } & Skill nurse & 12 & 30.8 & 100 \\
\hline \multirow{5}{*}{ Years' experience } & $<=8$ & 20 & 35.4 & 30.8 \\
\cline { 2 - 5 } & $9-17$ & 23 & 24.6 & 66.2 \\
\cline { 2 - 5 } & $18-26$ & 16 & 9.2 & 90.8 \\
\cline { 2 - 5 } & $27+$ & 6 & 100 \\
\hline
\end{tabular}

This table show that the study results for study sample by their demographic data that indicate the majority of the study samples are male $(62 \%)$ and age is (31-39) years old within age groups (34\%). Regarding occupations are their most from physician for application of the electronic health system $(49.2 \%)$ and years' experience for study sample (9-17) years $(35.4 \%)$.

Table (4) Distribution of the Study sample (health care providers) about their responses to feasibility for activating electronic health care system

\begin{tabular}{|l|l|c|c|c|}
\hline Overall domains & & Frequency & Percent & Cumulative Percent \\
\hline \multirow{5}{*}{ Feasibility domains } & Some extent feasibility & 11 & 16.9 & 16.9 \\
\cline { 2 - 5 } & Feasibility & 54 & 83.1 & 100 \\
\cline { 2 - 5 } & Not feasibility & 0 & 0 & \\
\cline { 2 - 5 } & Total & 65 & 100 & \\
\hline
\end{tabular}

This table show that the study results that indicate overall assessment for the responses of study samples are most of their responses about feasibility domain is feasibility (83\%) for healthcare providers about application of electronic health system. 


\section{Discussion}

The study finding depict overall assessment of responses for study samples were most of their responses(clients or patients) about feasibility domain was there is feasibility about for application of electronic health system. A similar study that indicates the impact of e-Health technologies more effectively, a fresh way of thinking is required about how technology can be used to innovate health care through application e-health that increase feasibility and quality of health care services (5). Other study is consistence with the current study that indicate feasibility and quality of health care by use electronic health system as Moreover, eight RCTs found improvement in patient symptoms following e-Health tool use, especially in adolescent asthma patients. Furthermore, three RCTs showed that e-Health tools might improve patient self-efficacy and selfmanagement of chronic disease. Little or no evidence was found to support the effectiveness of e-Health tools at improving medication recommendations and reconciliation by clinicians, medication-use behavior, health service utilization, adverse effects, quality of life, or patient satisfaction ${ }^{(6)}$.

The study results that indicate overall assessment about the sample responses (health care providers) about feasibility domain was there is feasibility for application of electronic health system. These finding is consistence with that found use of e-Health requires a certain degree of technical proficiency from both health care professionals ${ }^{(7)}$.

\section{Conclusions}

Conclusions for patients and clients results, most of the respondents were males with age's range from (35 to 55) years old and with Primary and Preparatory education. Nearly all participants found that activating electronic health care system were feasibility.

As for Conclusions for health care providers results, most of the respondents were males with age's range from (31 to 39) years old, most of the respondents were physicians with (8 to 17) years' experience. Most of the participants found that activating electronic health care system was feasibility.

\section{Conflict of Interest: Nil}

\section{Source of Funding: Self-funding}

Ethical Clearance: taken from ethical committee in nursing college/University of Baghdad. All protocols were approved by Iraqi Ministry of Health.

\section{References}

1. Della Mea V. What is e-Health (2): The death of telemedicine? Journal of medical Internet research. 2001; 3(2):e22.

2. Eysenbach, G. What is e-health? Journal of Medical Internet Research. 2001; 3 (2): e20.

3. Buntin MB, Burke MF, Hoaglin MC, Blumenthal D. The benefits of health information technology: a review of the recent literature shows predominantly positive results. Health affairs. 2011;30(3):464-71.

4. Resolution WH. 58.33. Sustainable health financing, universal coverage and social health insurance. Fifty-eighth World Health Assembly edition. Geneva: World Health Organization. 2005 May. http://apps.who.int/gb/ebwha/pdf_files/ WHA58REC1/english/A58_2005_REC1-en.pdf. Accessed 26 October 2016.

5. van Gemert-Pijnen JE, Nijland N, van Limburg M, Ossebaard HC, Kelders SM, Eysenbach G, Seydel ER. A holistic framework to improve the uptake and impact of eHealth technologies. Journal of medical Internet research. 2011; 13(4):e111.

6. Lancaster K, Abuzour A, Khaira M, Mathers A, Chan A, Bui V, Lok A, Thabane L, Dolovich L. The use and effects of electronic health tools for patient self-monitoring and reporting of outcomes following medication use: systematic review. Journal of medical Internet research. 2018; 20(12):e294.

7. Basnet $\mathrm{S}$, Tamminen M, Lahti T. The feasibility of eHealth in mental health care. J Addict Res Ther. 2014; 5(4):205. 